\title{
10 Exploring Communication Strategy Use and Metacognitive Awareness in the EFL Classroom
}

\author{
Henrik Bøhn and Gro-Anita Myklevold
}

\section{Introduction}

The term "communication strategies" (CSs) may be defined in a number of different ways, but typically it refers to strategies language learners adopt in order to solve communication problems (Bialystok 1990; Lam 2010; Zhang and Goh 2006). Examples of such strategies are circumlocution, code-switching (i.e. using L1 or L3 words) and appealing for help. In addition to the inclusion of problem solving as a defining feature of CSs, most conceptualisations also include a consciousness component (Dörnyei and Scott 1997). Thus, CSs may be said to be related to the concept of metacognition in the sense that language learners employing CSs may be more or less aware of their language behaviour (DeKeyser 2009). Metacognition in the context of this study refers to "an awareness of and reflections about one's knowledge, experiences, emotions and learning" (Haukås 2018, this volume).

In the CS research literature there have been conflicting views regarding the efficacy of CS teaching. Some researchers have found CS instruction to be of little value (Bialystok 1990; Ellis and Barkhuizen 2005; Kellerman 1991), but the majority of the studies carried out in this area have shown positive effects of such instruction on L2 learners' communicative effectiveness (e.g. Dörnyei 1995; Kongsom 2009; Lam 2010; Maleki 2007; Nakatani 2005). There are indications, however, that strategic language behaviour is highly complex, involving a number of factors which influence such behaviour (Dörnyei and Scott 1997). Examples of such factors are task effect, proficiency level, learning styles, attitude, anxiety, motivation and self-efficacy (Nakatani and Goh 2007). As research in this area is scarce, and many of the above-mentioned factors have not been examined, more studies are needed to better understand the relationship between these factors and strategy behaviour, as well as how CS teaching may be employed to improve strategy use (Nakatani and Goh 2007).

The present study explores the potential effects of CS instruction on the use of strategies in a group of English as a Foreign Language (EFL) students at the lower secondary school level in Norway. It also investigates 
the question of how students' metacognitive awareness may impact on the quality and quantity of the strategies used. In addition, the influence of the students' proficiency level and motivation will be examined.

\section{Literature Review}

The term "communication strategies" (CSs) was introduced in the early 1970s to describe identifiable approaches adopted by foreign/second language learners in order to communicate in the L2 (Selinker 1972). Since then, a number of different definitions and typologies of CSs have been developed. These can be crudely associated with two major approaches to the study of CSs, i.e. the psycholinguistic view and the interactional view (Rahmani Doqaruni 2015). The former has mainly been concerned with studying how language learners handle communication problems when their linguistic resources are inadequate, by, for example, using lexicalcompensatory and other cognitive processes (Bialystok 1983; Kellerman and Bialystok 1997; Poulisse 1990). The latter has chiefly been preoccupied with how interlocutors interact and negotiate meaning. This entails not only a focus on problem-solving mechanisms, but also on how learners use CSs as pragmatic discourse devices to get their message across (Corder 1983; Tarone 1980; Williams, Inscoe, and Tasker 1997).

In this chapter, we adopt the psycholinguistic view and define CS use as "strategies adopted by L2 learners in order to manage communication problems" (cf. Dörnyei and Scott 1997; Nakatani and Goh 2007). On this view, CSs can be divided into reduction strategies and achievement strategies (Færch and Kasper 1983; Rossiter 2003). The former refer to approaches speakers use to adapt their original message to their communicative resources by changing, reducing or abandoning the original content. One such strategy is "topic avoidance". The latter refer to strategies used to try to retain the intended content, despite lack of linguistic resources, by manipulating the available language system. Examples of achievement strategies are "approximation", "circumlocution" and "semantic word coinage" (e.g. using the word mini-lobster for "crawfish"). Obviously, achievement strategies are generally preferable to reduction strategies in helping to convey messages, but some achievement strategies, such as "code-switching", may have a detrimental effect on communication.

As mentioned previously, there is widespread consensus that communication strategies include a consciousness component, reflected in the notion that a "strategy" is something that L2 speakers employ consciously with the intent to achieve one or more communicative goals. Although consciousness may be seen as a vague concept, there is some consensus that it pertains to the attention paid by language users to one or more strategies being employed (Dörnyei 2009; cited in Cohen 2011, 11). In this respect, consciousness can be regarded as relating to the concept of metalinguistic awareness, involving "metacognitive knowledge about one's linguistic behaviour" (DeKeyser 
2009, 123). Moreover, it can be said to involve metacognitive strategies, defined as "preassessment and preplanning, online planning and monitoring, and postevaluation of language learning activities and of language use events" (Cohen 2011, 19). Research on the relationship between CS use and metacognition is scarce, however (Zhang and Goh 2006). In the following, we will use the terms "metacognitive strategies" and "metacognitive awareness" to refer to learners' metacognition in CS use.

Studies of CS instruction have mainly investigated the effects of strategy instruction on learners' qualitative and quantitative uses of CSs (Nakatani and Goh 2007), as well as on the proficiency levels and/or task performance of the research participants. In addition, some studies have examined the impact of instruction on students' attitudes towards the usefulness of CSs and CS instruction (e.g. Dörnyei 1995; Nakatani 2005; Zhang and Goh 2006). In the following review, we will report on studies which are of direct relevance to our investigation, i.e. studies investigating the effect of instruction on learners' proficiency levels and/or use of strategies, as well as studies examining the connection between metacognition and strategy use.

One study, Dörnyei (1995), investigated the effects of a six-week communication strategy training programme on 53 Hungarian EFL learners, aged $15-18$, using a pre- and post-test design. The study examined the use of the strategies "topic avoidance and replacement", "circumlocution" and "using hesitations and filling devices". The students underwent the six-week training programme as part of their official secondary school English course, in which they received explicit training in three lessons each week. The instruction included the presentation of linguistic devices to verbalise CSs, the provision of models of good CS use, awareness-raising of the communicative potential of CSs and examples of cross-cultural differences in CS behaviour. In addition, the students were encouraged to take risks using CSs, and they were given the opportunity to practice using the strategies. A control group comprising 56 students received no training. The instrument for eliciting spoken performance was a monologue task, and the students in the experiment group were also asked about their attitudes towards this type of training at the end of the instruction phase. The results indicated that students in the treatment group performed significantly better on the post-test than the students in the control group with regard to the quality of circumlocutions and the frequency of fillers and circumlocutions. The students were also generally favourable towards the training. On the basis of the results, it was concluded that CS instruction may improve the frequency and quality of strategy use.

In another investigation, Scullen and Jourdain (2000) also used pre- and post-tests to study the effects of CS instruction on foreign language learners. The treatment group comprised 17 US undergraduate students studying French as a foreign language. The control group consisted of a similar cohort of eight students. The intervention entailed the explicit teaching of various kinds of circumlocution techniques ("analogy", "function" and 


\section{Henrik Bøhn and Gro-Anita Myklevold}

"description strategies") in three separate sessions. The findings showed that the students in both the treatment and the control groups made significant gains in their quantitative and qualitative use of CSs over time. Hence, the study could not support the assumption that CS training is preferable to "regular" instruction when it comes to improving students' use of CSs.

Rossiter (2003) investigated the effects of CS instruction on strategy use and L2 performance (communicative success, speech rate, message abandonment). A group of 30 adult immigrant ESL students in Canada were divided into a communication strategy group $(n=15)$ and a comparison group $(n=15)$. The communication strategy group was given strategy training in 12 separate lessons involving the use of "approximation", "superordination", "analogy", "all-purpose words" and "circumlocution". In addition to explicit instruction in the use of these strategies, the classes also involved explicit awareness-raising training. Performance was elicited by means of a picture description task and an object description task, and the students were also asked to report on the usefulness of the CS training. The results showed that the quantity of the strategies was higher for the experiment group than for the control group after treatment, but the study could not document improved L2 performance. There were also clear indications that the students found the training beneficial. Rossiter concluded that more empirical evidence must be gathered before advice on when, how and which strategies to teach should be distributed to language instructors.

In an intervention study involving 62 Japanese EFL students at a private college in Japan (age 18-19), Nakatani (2005) investigated the effects of CS instruction on speaking proficiency and students' discourse. The CSs taught to the experimental group $(n=28)$ were "help-seeking", "modified interaction", "modified output", "time-gaining", "maintenance" and "selfsolving" strategies. The intervention took place in the course of a 12-week instructional programme involving 90-minute sessions each week. Explicit awareness training was provided in addition to a focus on the five different CS devices. The results showed that the treatment group improved their oral proficiency significantly more than the control group. There were also clear indications that they improved their discourse (e.g. length of utterances, ability to maintain conversation flow) significantly more than the students who received no training. In addition, there was evidence that the students in the experimental group became more conscious of how to use CSs, as well as how to recognise the usefulness of applying such strategies.

Kongsom (2009) examined the effects of CS teaching on 62 EFL university students in Thailand. The students were given 12 weeks of CS instruction (12 lessons) focusing on nine strategies: "pause fillers and hesitation devices", "approximation", "self-repair", "circumlocution", "confirmation check", "topic avoidance", "appeal for help", "clarification request" and "comprehension check". Specific emphasis was placed on enhancing the students' awareness of CSs. 12 students were singled out as research participants. Pre- and post-tests in the form of monologue and discussion tasks were conducted in order to measure the students' use of strategies (qualitatively 
and quantitatively). Moreover, questionnaires and retrospective protocols were carried out in order to analyse the learners' use of strategies as well as their attitudes towards the use of CSs. The results indicated that the students were to some extent able to successfully use the nine strategies taught at the end of the programme, particularly pause fillers and hesitation devices. The results also showed that they found the CSs, and especially pause fillers and hesitation devices, to be useful. Finally, there was evidence that they became more aware of the use of CSs after instruction and that they found this type of instruction to be valuable.

Finally, Lam (2010) studied the impact of CS teaching on 20 adolescent ESL students (aged 13-14) in Hong Kong with regard to the students' task performance and self-reported strategy use (qualitative and quantitative). 20 students in a corresponding cohort made up the control group. The strategies training class received specific instruction with regard to eight CSs: "resourcing”, "paraphrasing”, "use of fillers", "self-repetition", "use of selfcorrection", "asking for repetition", "asking for clarification" and "asking for confirmation". Additionally, the students were specifically instructed to reflect on and evaluate individual performance. The experiment class was given eight instructional sessions over a period of five months (one semester). The potential effects of the intervention were measured by means of external raters' assessments of group discussions and verbal protocol methodology. The analyses were further refined to study the performances of high- and low-proficiency students in both the experiment and the treatment group. The results showed that only the low-proficiency students in the treatment group showed sustained increases in their use of strategies. They also indicated that the low-proficiency students in the experimental class had higher gains in their proficiency scores than the other students. In addition, there were indications that they were able to reflect more than the students in the control group on their own performances in the tasks.

In summary, the majority of the studies included in this review indicate that CS training may have positive effects on students' qualitative and quantitative use of strategies. Some studies also found positive effects on general speaking performance. However, a number of limitations in these studies must be recognised: (1) They examined only a restricted number of strategies, (2) they generally did not examine the same strategies, (3) the student groups involved were considerably heterogeneous, and (4), as was mentioned in the introduction, a number of other variables may have affected speaking performance. Hence, more studies are needed (Nakatani and Goh 2007).

\section{The Current Study}

\section{Aim}

The following study explores the extent to which instruction targeting the use of approximation, circumlocution, superordination and use of fillers / stalling strategies may positively affect the quality and quantity of 
Norwegian intermediate EFL learners' use of such strategies. Moreover, the study considers the degree to which the use of these strategies is linked to the students' metacognitive awareness of them, as well as to what extent the proficiency and motivation levels of the students play a role. The following research questions (RQs) are addressed:

1. To what extent does the teaching of approximation, circumlocution, superordination, and use of fillers / stalling strategies affect the quantity and quality of Norwegian students' use of such strategies?

2. To what extent do students' metacognitive strategies have an impact on the quality and quantity of their use of CSs?

3. To what extent do the students' proficiency levels affect the use of CSs?

4. To what extent does motivation have an impact on the use of CSs?

\section{The Context of the Study}

Although English is neither a first nor an official language in Norway, it has a strong position in Norwegian society. It is taught as a compulsory school subject from the first school year (age six), and people are widely exposed to English both inside and outside of school. Studies have shown that the general proficiency level of the population is high (Education First 2015), and people use English for a number of different purposes across a range of different contexts, both nationally and internationally.

The latest version of the Norwegian national curriculum was introduced in 2006 and is largely based on the Common European Framework of Reference (CEFR) (Council of Europe 2001). The English subject curriculum includes several metacognitive competence aims, such as the ability to "use different situations, working methods and learning strategies to develop one's English-language skills" and to "comment on own work in learning English" (Norwegian Ministry of Education and Research 2006/2013). In research on 21st-century skills in Norway, metacognition is regarded as one of the four most prominent skills that should be developed in future classrooms (NOU 2015: 8 2015).

In lower secondary school in Norway, students aged 14-16 have, on average, reached an intermediate proficiency level in English (CEFR, level B1). End-of-instruction assessment is primarily given in the form of overall achievement marks, awarded by each individual subject teacher on the basis of various forms of classroom assessment. Grades range from 1 ("fail") to 6 ("excellent").

\section{Participants}

The students were non-randomly recruited through a collaborative project between the institution of one of the researchers and the students' school. They were in their final year of lower secondary school (age 15-16). A class 
of 22 students comprised the strategies instruction group, who received explicit CS teaching; another class of 13 students, who received only regular instruction, made up the control group. The classes were unevenly distributed, as the larger class consisted of two separate groups which had recently been merged. All the students in both groups were given a questionnaire which asked about their grades, their motivation for learning and speaking English and their metacognitive awareness related to their use of CSs when speaking English (see also Zhang and Qin 2018, this volume, for a questionnaire study on writing strategies in multimedia settings). In addition, five students in the strategies instruction group and five in the control group were purposefully selected (Creswell 2013) for a post-intervention test and post-test introspective interviews. These instruments were intended to elicit information about the students' qualitative and quantitative use of CSs, as well as their degree of metacognitive awareness related to CS use. We deliberately chose students at different proficiency levels for the test and the interviews, making sure that there were students at the lower levels (grades 2-3), intermediate level (grade 4) and higher level (grades 5-6) in both groups (cf. Tables 10.1 and 10.2).

\section{Instruments}

The choice of CSs to be taught was made on the basis of a brief analysis of the students' communicative needs, as reported by their teachers, as well as research on what EFL instructors emphasise in their assessment of oral L2 English performance (Bøhn 2016). As the teachers mentioned

Table 10.1 Overview of the use of CSs by students in the treatment group $(n=5)$.

\begin{tabular}{lcccccc}
\hline & Cand. 6 & Cand.7 & Cand.8 & Cand.9 & Cand.10 & TOTAL \\
\hline Students' grade level & 5 & 3 & 2 & 4 & 4 & \\
Good quality CS & 27 & 23 & 8 & 30 & 13 & 101 \\
Medium quality CS & 21 & 48 & 36 & 52 & 32 & 189 \\
Poor quality CS & 6 & 23 & 19 & 18 & 9 & 75 \\
Total & 54 & 94 & 63 & 100 & 54 & 365 \\
\hline
\end{tabular}

Table 10.2 Overview of the use of CSs by students in the comparison group $(n=5)$.

\begin{tabular}{lcccccc}
\hline & Cand.1 & Cand.2 & Cand. 3 & Cand. 4 & Cand. 5 & TOTAL \\
\hline Students' grade level & 3 & 4 & 4 & 5 & 3 & \\
Good quality CSs & 4 & 19 & 8 & 7 & 17 & 55 \\
Medium quality CSs & 22 & 34 & 10 & 21 & 27 & 114 \\
Poor quality CSs & 27 & 9 & 6 & 6 & 9 & 57 \\
Total & 53 & 62 & 24 & 34 & 53 & 226 \\
\hline
\end{tabular}


limited vocabulary as a potential disadvantage for a number of students, it was deemed relevant to focus on strategies which could compensate for this deficiency. Moreover, as teacher raters are reported to value performance aspects such as range of linguistic resources and ability to provide extensive responses in the assessment of student performance (Bøhn 2015; Borger 2014), we found it appropriate to include achievement strategies which could help the students recount, describe and explain subject content. Hence, we chose the following CSs, using Dörnyei and Scott's (1997) and Rossiter's (2003) taxonomies:

i Circumlocution: Describing, illustrating or exemplifying the characteristics of the target item or action, e.g. you use it to stay dry in the rain for "umbrella".

ii Approximation: Using a related term which shares semantic properties with the target word, e.g. moose for "deer".

iii Superordination: Using a generic term (hypernym) which semantically subsumes the target word or phrase, e.g. bird for "ostrich".

iv Use of fillers / stalling strategies: The employment of "filling words" or gambits in order to fill pauses and to gain time to think, e.g. well, let me see, it seems that.

The post-intervention test used to elicit the students' use of CSs consisted of an object description task and a picture description task. The object description task included six items which the students, according to their teacher, would probably not know the English words for, such as pruning shears, (forestry) harvester and sloth (animal). The picture description task contained a drawing of a couple making food in a kitchen, including a number of foodstuffs and kitchen utensils. The students were asked to describe the kitchen situation in as much detail as possible.

In order to investigate the students' metacognitive awareness, we used introspective interviews (Sasaki 2014). The interviews comprised questions related to the students' perceived difficulty of the object description and picture description tasks, as well as questions concerning whether they had used CSs when answering the tasks. The students were also asked about whether they used CSs when speaking English generally, and whether they were conscious of doing so. All the interviews were conducted in Norwegian.

The questionnaires were also provided in Norwegian and contained questions related to background variables (gender, first language), grades, motivation for learning and using English, as well as items concerning the students' use of CSs and their metacognitive awareness related to such use. The different items included operationalisations of the four CSs mentioned above. For example, for superordination, one item read: "Whenever I have to explain something in English, but cannot find the word, I try to find a more general word than the one I am looking for; for example, animal for "guinea pig'". The answers were given on a five-point Likert scale ranging 
from "To a small degree" to "To a large degree". A reliability analysis of the items measuring metacognitive awareness yielded a Cronbach's alpha of $\alpha=.75$, which is acceptable.

\section{Procedure}

The intervention was introduced to the experiment group at the beginning of the semester by one of the researchers, who explained the project and introduced the students to the use of CSs through a two-hour teaching session. In addition to presenting the four concrete CSs of the project, and their relevance for developing good communication skills, the researcher also specifically informed the students of the significance of metacognitive strategies. This entailed a focus on the value of attending consciously to the challenge of the communicative task and one's own communicative resources, as well as awareness of the CSs and how they could potentially be used to manage the communication problems that were identified. Hands-on CS tasks were provided to help familiarise the students with the strategies and with the metacognitive awareness-raising. For example, for circumlocution, the students were given a number of pictures of objects they had to explain to a peer without using the words representing them. Model phrases were provided, such as "It is an object / a living thing", "It is big/small/medium-sized", "It is made of metal/wood/fabric/plastic". After the introductory session, the students attended three additional two-hour sessions throughout the semester provided by their regular English teacher; these sessions involved presentations of the strategies, model uses and relevant tasks to be carried out by the students.

At the end of the semester, the post-intervention CS test was given to the five students in the experiment and the five students in the comparison group, as explained under 'Participants' above. Immediately after the tasks were completed, they were interviewed about their use of CSs in the tasks, and their use of English generally, in order to examine their metacognitive awareness with respect to the use of CSs. Both the task responses and the introspective interviews were recorded on an Olympus DM-450 digital voice recorder and subsequently transcribed.

\section{Data Analyses}

The recorded transcripts from the post-tests and verbal retrospective reports were transcribed by the researchers. The transcripts were analysed by means of the computer programme QSR NVivo10. In order to answer RQ1, we analysed the transcripts from the post-tests by means of protocol coding (Miles, Huberman, and Saldaña 2014), using Dörnyei and Scott's (1997) and Rossiter's (2003) classifications of the strategies circumlocution, approximation, superordination and use of fillers / stalling strategies.

First, the transcripts were divided into ideas units. An ideas unit can be defined as "a single or several utterances with a single aspect of the event 
as the focus", i.e. a unit "concerned with a distinct aspect of performance" (Brown, Iwashita, and McNamara 2005, 13). The following excerpt, divided into 15 units (each separated by "/") provides an illustration:

[In picture 3 there is]/an animal (1)/who ... is up in a tree (2)/It has a
lot of fur (3)/and it has long (4)/nails (5)/It is a bit ugly in the face (6)/
but also a little cute (7)/The fur is brown ... (8)/and . . the nails (9)/in
kind of way is white (10) / . . er (11)/It lives in a zoo (12)/I think (13)/
and maybe in Australia (14)/I don't know (15).

These ideas units were then assigned to the CS categories listed in Dörnyei and Scott's (1997) and Rossiter's (2003) classifications. For example, in the above, unit (1), an animal, was coded as "superordination". Units (2)(4), (6) — (8), (10), (12) and (14) were coded as "circumlocution". Units (5) and (9) were classified as "approximation", units (11) and (13) were coded as "use of fillers / stalling strategies", and (15) was characterised as "verbal strategy marker".

In order to determine the quality of the strategies used, we recruited a lower secondary school English teacher to help us categorise the CSs and the corresponding student statements as either "good quality", "medium quality" or "poor quality". These categorisations were based on evaluations of how successfully the statements actually described the items and situations presented in the two tasks. Three major deliberations in this evaluation process are worth mentioning. First, we concluded that two of the strategies taught in the intervention, i.e. superordination and use of fillers / stalling strategies, clearly belonged in the "good quality" category. Second, we decided that approximation could also be considered a "good quality" strategy, even though some of the student statements did not provide very good task descriptions. For example, when Candidate 6 was trying to describe a wheelbarrow, she used the word sticks for "handles". Still, most of the approximations used, such as garden scissors for 'pruning shears', were deemed qualitatively good. Third, it became clear that a number of the circumlocutions employed by the students did not explain the different objects very well. For example, when trying to describe the word trailer, one student said "you can drive the things you want easier". This was then classified as a poor-quality circumlocution. Conversely, the statement "it is a kind of box you can attach to the back of your car ... with wheels on" was classified as a good quality circumlocution.

Beyond the use of the four intervention strategies specifically targeted here, the students also employed a number of other CSs, such as all-purpose words, code-switching and message abandonment, and we correspondingly categorised all these strategies as either high, medium or low. The overall classification of the quality of the CSs can be accessed from www.fag.hiof. no/ heb/CS-Findings.pdf. 
To answer RQ2 we analysed the post-test interviews with a view to identifying the students' metacognitive strategies when using CSs. The interview transcripts were divided into ideas units in a way similar to the test transcripts described above. Provisional coding (Miles, Huberman, and Saldaña 2014) was used to analyse the student statements. This was accomplished by establishing a list of categories related to metacognitive awareness, as defined in the introduction (cf. above). This list comprised the categories "preassessment, "preplanning", "online planning/monitoring" and "postevaluation" (Cohen 2011), as well as "attention" (Dörnyei 2009). We defined "attention" as "attention to communication challenges, own communicative resources, and communicative strategies available". In order to identify cases where the students explicitly denied using CSs when directly asked about it, we also created a category labelled "No conscious use of CSs" (cf. Table 10.3 below). Beyond the provisional coding, we also employed descriptive coding (Saldaña 2013) to allow for the analysis of possible explanations for the use or non-use of metacognitive strategies, as well as to explore other relevant aspects of the students' use of these strategies.

RQ3 and RQ4 were answered using data from the questionnaire. In the questionnaire the students were asked to report on their latest end-of-semester grade in English, on their motivation for learning English, on the extent to which they used the CSs which had been taught to the intervention group, and on the degree to which they were thinking consciously about these strategies. More specifically, the motivation construct was operationalised using three items, two of which were based on Cohen's (2011) definition of motivation, i.e. "how much [students] like learning the particular language" and "how important it is for them to learn [the] language" (42). The third item was formulated as: "To what extent do you think speaking English is fun?".

Since the measures of CS use obtained by the questionnaire may be regarded as somewhat undependable, insofar as they were based on selfreports, we compared the ten test takers' use of CSs in the two tasks with their questionnaire responses in order to examine the degree of correspondence between self-reported and actual use of the strategies. This analysis showed that there was fairly good agreement between self-reported and actual use in the intervention group, whereas there was some more discrepancy in the non-intervention group. However, as we only wanted to investigate the impact of grades and motivation on CS use in the intervention group, we considered the answers given by the intervention students to be sufficiently reliable to warrant dependable answers. Still, we regard the self-reported measures as a weakness in this study.

The relationships between grade level and reported use of CSs, and between motivation and reported use of CSs, were explored using Somer's $d$. This is a nonparametric measure which is suitable when investigating the strength and direction of association between two ordinal variables (Lærd Statistics n.d.). First, we therefore ran the Somers' $d$ test to analyse the association 
between the grade level item and the four items representing the strategies approximation, circumlocution, superordination and use of fillers / stalling strategies. Second, we ran the test to determine the relationship between each of the three items operationalising the motivation construct and the same four strategies.

\section{Findings}

\section{Results for RQ1}

The analysis of the data for RQ1 showed that the students in the treatment group used a considerably higher number of communication strategies $(n=365)$ than the students in the comparison group $(n=226)$. Table 10.1 and Table 10.2 give an overview of the quantitative and qualitative uses of CSs by the different students (Complete versions of the tables can be found in Appendix).

As can be seen from Table 10.1 and Table 10.2, the students in the treatment group used 101 good quality CSs, while the comparison group used 55. In other words, the students in the treatment group used nearly twice as many of the strategies they had been taught compared to the non-treatment group. In addition, it is interesting to observe that four of the five students in the intervention group used all the CSs they had been taught. The fifth student (Cand. 9) used three of the four strategies. Conversely, only one student in the non-treatment group employed all four CSs. The others used three (two students) or two (two students) strategies.

As for the use of the four strategies included in the intervention, circumlocution was by far the most frequently used category by both groups ( $40 \%$ in the intervention group; $61 \%$ in the comparison group). Conversely, approximation was the least frequently used category by the intervention group $(12 \%)$, whereas use of fillers / stalling strategies was the least frequently used category by the non-treatment group (4\%) (cf. Table 10A.1 and Table 10A.2, Appendix).

However, it is also worth noting that the treatment group employed a significantly higher number of CSs which they had not been taught, i.e. the medium and poor quality CSs. As can be seen from the two tables above, the treatment group used 189 instances of medium quality strategies and 75 instances of poor quality strategies, as against the comparison group's 114 and 55 . We will return to a closer analysis of these findings in our discussion below.

\section{Results for $R Q 2$}

RQ2, which examined the relationship between metacognitive strategies and the use of CSs, was answered with data from the post-test interviews. The results showed that all of the students reported being conscious of their use of 
at least one achievement strategy (such as circumlocution, superordination or appealing for help). Tables 10.3 and 10.4 give an overview of the responses. The categories in the light grey cells indicate instances where the students reported being conscious of using the different CS strategies listed; the categories in the dark grey cells indicate instances where the students denied being conscious of strategies, when they were asked specifically about them.

A summary of the responses in Tables 10.3 and 10.4 demonstrates that the students in the intervention group on average reported being aware of 2.8 metacognitive strategies, whereas the students in the comparison group were aware of 1.6 strategies. The following exchange between one of the researchers and Candidate 1 , who had not received any instruction, serves as an illustration:

RESEARCHER: If you encounter a situation where you don't know the meaning of a word, such as in this test, what do you do?

INTERVIEWEE: I do try to think about what to say, right . . . But if it's completely impossible, I usually ask the teacher what it is.

As can be seen from this response, the student is aware of the possibility of appealing for help as a last resort. However, as the tasks used in this investigation were monologue tasks, it is difficult to know whether this candidate

Table 10.3 Degree of metacognitive awareness of CS use: intervention group $(n=5)$.

\begin{tabular}{|c|c|c|c|c|c|}
\hline & Cand. 6 & Cand. 7 & Cand. 8 & Cand. 9 & Cand. 10 \\
\hline Grade & 5 & 3 & 2 & 4 & 4 \\
\hline $\begin{array}{l}\text { Conscious use of .... } \\
\text { Approximation } \\
\text { Circumlocution } \\
\text { Use of fillers / stalling strategies } \\
\text { Superordination }\end{array}$ & $\begin{array}{l}\sqrt{ } \\
\sqrt{ } \\
\sqrt{ }\end{array}$ & $\begin{array}{l}\sqrt{ } \\
\sqrt{ }\end{array}$ & $\sqrt{ }$ & $\begin{array}{l}\sqrt{ } \\
\sqrt{ }\end{array}$ & $\sqrt{ }$ \\
\hline $\begin{array}{l}\text { All-purpose words } \\
\text { Appealing for help } \\
\text { Asking for clarification } \\
\text { Avoiding code-switching } \\
\text { Mime } \\
\text { Self-repair } \\
\text { Verbal strategy marker }\end{array}$ & $\begin{array}{l}\sqrt{ } \\
\sqrt{ }\end{array}$ & & $\begin{array}{l}\sqrt{ } \\
\sqrt{ }\end{array}$ & $\sqrt{ }$ & \\
\hline $\begin{array}{l}\text { No conscious use of .... } \\
\text { Approximation } \\
\text { Circumlocution } \\
\text { Use of fillers / stalling strategies } \\
\text { Superordination }\end{array}$ & $\sqrt{ }$ & $\sqrt{ }$ & $\begin{array}{l}\sqrt{ } \\
\sqrt{ } \\
\sqrt{ }\end{array}$ & $\begin{array}{l}\sqrt{ } \\
\sqrt{ }\end{array}$ & $\begin{array}{l}\sqrt{ } \\
\sqrt{ }\end{array}$ \\
\hline $\begin{array}{l}\text { Appealing for help } \\
\text { Asking for clarification } \\
\text { Mime }\end{array}$ & & $\sqrt{ }$ & & $\sqrt{ }$ & $\sqrt{ }$ \\
\hline
\end{tabular}


Table 10.4 Degree of metacognitive awareness of CS use: comparison group $(n=5)$.

\begin{tabular}{|c|c|c|c|c|c|}
\hline & Cand. 1 & Cand. 2 & Cand. 3 & Cand. 4 & Cand. 5 \\
\hline Grade & 3 & 4 & 4 & 5 & 3 \\
\hline $\begin{array}{l}\text { Conscious use of ... } \\
\text { Approximation } \\
\text { Circumlocution } \\
\text { Use of fillers / stalling strategies } \\
\text { Superordination }\end{array}$ & & & $\sqrt{ }$ & $\sqrt{ }$ & \\
\hline $\begin{array}{l}\text { All-purpose words } \\
\text { Appealing for help } \\
\text { Asking for clarification } \\
\text { Avoiding code-switching } \\
\text { Mime } \\
\text { Self-repair }\end{array}$ & $\sqrt{ }$ & $\sqrt{ }$ & $\sqrt{ }$ & $\begin{array}{l}\sqrt{ } \\
\sqrt{ }\end{array}$ & $\sqrt{ }$ \\
\hline $\begin{array}{l}\text { No conscious use of .... } \\
\text { Approximation } \\
\text { Circumlocution } \\
\text { Use of fillers / stalling strategies } \\
\text { Superordination }\end{array}$ & $\begin{array}{l}\sqrt{ } \\
\sqrt{ } \\
\sqrt{ } \\
\sqrt{ }\end{array}$ & $\begin{array}{l}\sqrt{ } \\
\sqrt{ } \\
\sqrt{ }\end{array}$ & $\begin{array}{l}\sqrt{ } \\
\sqrt{ } \\
\sqrt{ }\end{array}$ & $\begin{array}{l}\sqrt{ } \\
\sqrt{ } \\
\sqrt{ }\end{array}$ & $\begin{array}{l}\sqrt{ } \\
\sqrt{ } \\
\sqrt{ } \\
\sqrt{ }\end{array}$ \\
\hline $\begin{array}{l}\text { Appealing for help } \\
\text { Asking for clarification } \\
\text { Mime } \\
\text { Transferring CSs from L1 } \\
\text { Use of anticipation-retrieval } \\
\text { Use of CSs in pre-planned task }\end{array}$ & $\sqrt{ }$ & $\begin{array}{l}\sqrt{ } \\
\sqrt{ } \\
\sqrt{ } \\
\sqrt{ }\end{array}$ & & & $\sqrt{ }$ \\
\hline
\end{tabular}

would actually use appealing for help when experiencing communication difficulties. Hence, our analysis of the effect of metacognition on the use of CSs is based on a comparison between reported metacognitive awareness (cf. Tables 10.3 and 10.4) and the types of CSs used in the post-intervention test (cf. Tables 10.1 and 10.2). When comparing these results, we found that the students in the intervention group actually used those strategies that they had paid attention to more frequently than the strategies they had not paid attention to. For example, Candidate 6 reported being aware of approximation, circumlocution and superordination (cf. Table 10.3), and she de facto used these strategies more frequently than stalling strategies (cf. Table 10.1). Admittedly, these differences were not substantial in all cases. As can be seen, Candidate 6 used five instances of approximation, six instances of superordination (which she claimed to be aware of) and four instances of use of fillers / stalling strategies (which she did not mention). Yet, the tendency for conscious use of strategies is interesting and is supported by the findings in the comparison group, in which the two candidates (4 and 5) who claimed to be aware of one strategy each, namely circumlocution, used it more than the other strategies (cf. Tables 10.2 and 10.4). 
Beyond these findings, it is worth mentioning that none of the students in the intervention group actually reported being consciously aware of using all the four strategies that they had been taught. Moreover, three of them (7, 8 and 9) exhibited a somewhat ambiguous orientation towards metacognitive awareness in general. Even though they confirmed being conscious of the use of circumlocution, they sometimes contradicted themselves when responding to questions about other strategies or CS in general. The following exchange between the researcher and Candidate 9 is a case in point:

RESEARCHER: When you encounter a word that you don't know . . . for example forestry harvester . . . do you then think about using a more general expression?

INTERVIEWEE: That's what I did now. I said that it was a machine, but I said it was something one uses to make it more efficient to . . cut down trees.

Here the student confirms being aware of superordination as a strategy. However, when he later mentioned a real-life situation where he had to speak English, and the researcher asked about his conscious use of CSs, the student was less clear about his metacognitive awareness:

RESEARCHER: So you acted as an interpreter [for your father]? That's good! But in such cases, do you then think that 'Now I have to use body language' or 'Now I have to use some other strategy'? Or do you just speak?

INTERVIEWEE: No, I just speak.

Hence, with the exception of circumlocution, it appears that the metacognitive aspects of the strategy instruction had not induced these three students to systematically plan, monitor and evaluate their CS to any considerable degree.

\section{Results for RQ3}

Regarding RQ3, i.e. the association between grade level and use of CSs, the results from the Somers' $d$ test showed that there was no statistically significant relationship between these two variables in the intervention group $(n=22)$. When considering individual responses to the items, it became clear that, for example, four grade 4 students, three grade 5 students and three grade 6 students reported using circumlocution to a fairly high extent (point 4 on the Likert scale). However, one grade 2 student reported using circumlocution to a very large extent (point 5 on the Likert scale). Conversely, one grade 4 student indicated very little use of this strategy (point 1 on the Likert scale) and one grade 5 student also testified to employing circumlocution to a limited degree (point 2 on the Likert scale). When comparing these results 
with the intervention test group's actual use of strategies (cf. Table 10.1), it can be seen that the strongest student (Cand. 6) used the least number of strategies $(n=53)$, whereas the least proficient student (Cand. 8) used more strategies than both Candidate 6 and Candidate 10. Moreover, the second least proficient student (Cand. 7) used as many as 94 strategies. Hence, it is difficult to discern a pattern to explain the relationship between grade level and use of CSs in this data.

\section{Results for RQ4}

RQ4, i.e. the degree to which there was a correspondence between motivation and use of CSs, was also answered with data from the questionnaire. The results from the Somers' $d$ test yielded only one statistically significant measure. We found a moderate, positive correlation between the item 'I think the English subject is fun' and the reported use of circumlocution $(d=.399, p=.003)$. In other words, the more 'fun' the students found the English subject, the more they used the CSs. However, as there were three items measuring motivation and four items measuring CSs (i.e. a total of 12 correlations investigated), there is not much evidence to support the claim that motivation played any important role in these students' use of CSs. A more specific analysis of the students' responses to the different items showed, for example, that highly motivated students reported using few strategies, whereas less motivated students claimed that they used strategies to a high degree. One example is the association between the item 'I want to improve my speaking skills' and self-reported use of approximation. In Figure 10.1, the results from this analysis have been visualised in a clustered bar chart.

As can be seen in Figure 10.1, three students who reported being highly motivated also reported using strategies to a low or fairly low degree (cf. the white and black bars to the far right in the chart). Conversely, three students who testified to being moderately motivated claimed to use strategies to a high or fairly high degree (cf. the light and dark grey bars in the middle of the chart). Thus, it was difficult to identify a consistent pattern in the association between these variables.

\section{Discussion}

The analysis of the effect of CS instruction on students' use of strategies (RQ1) showed that the students who were given explicit teaching used nearly twice as many of the strategies taught compared to the students who received no instruction. This result corroborates the findings by Dörnyei (1995), Lam (2010) and Kongsom (2009). The teaching of such strategies, most of which were classified as "high quality CSs" in this study, is therefore something that may be efficacious in foreign language teaching at the intermediate proficiency level. However, the fact that the students in the 


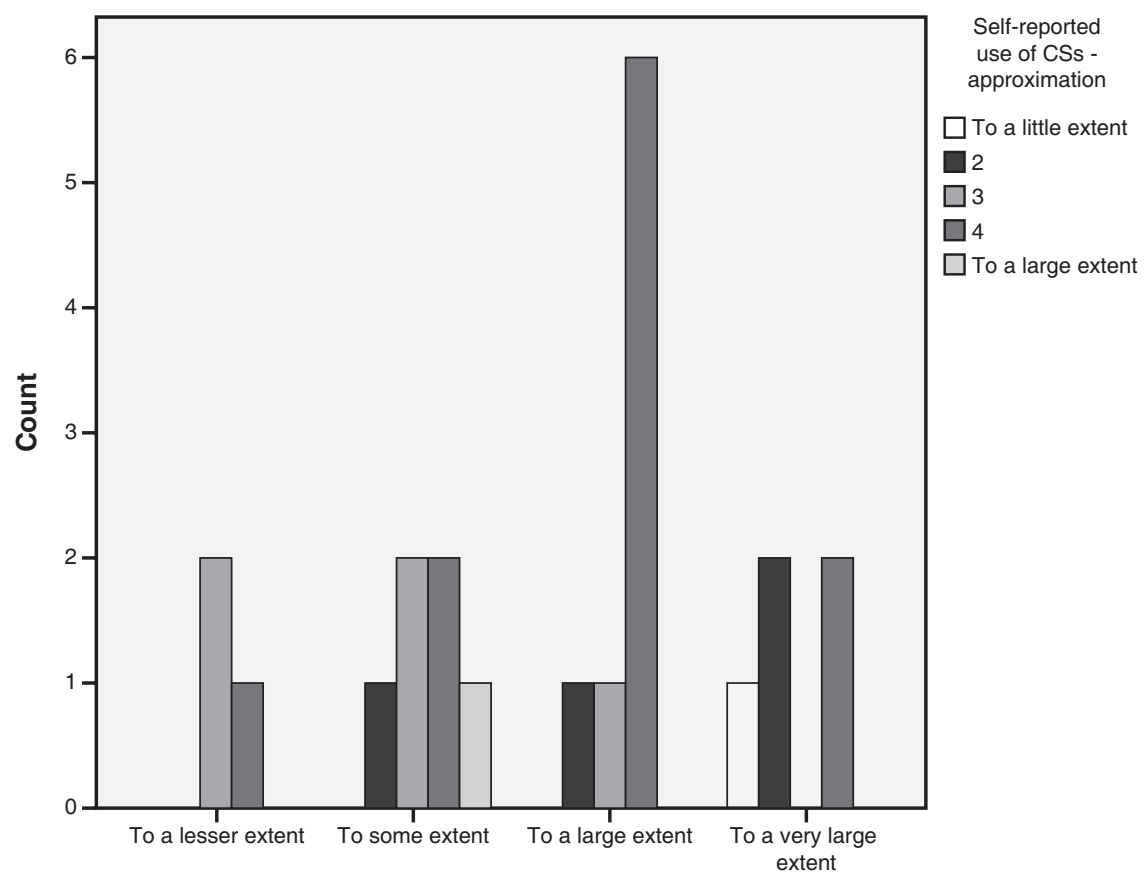

Motivation - I want to improve my speaking skills

Figure 10.1 Correlation between self-reported motivation and use of approximation $(n=22)$.

intervention group also employed a higher number of poor quality CSs (75 instances as against the comparison group's 57 ) is something which may contradict the usefulness of CS instruction. However, we believe this result may be attributed to the fact that the students in the intervention group, on average, gave more elaborate descriptions of the items in the tasks. The average number of words used by the treatment group students was 450 ; the corresponding number for the control group was 386 . Hence, had the students in the comparison group produced equally extensive responses, they may also have used a larger number of poor quality strategies.

Beyond this, there seems to be a relationship between the students' linguistic resources and their ability to produce good quality circumlocutions. For example, a comparison of Candidate 6 (grade level 5) with Candidate 8 (grade level 2) shows that the former produced 27 good quality CSs compared to eight by the latter. In other words, the better their proficiency, the more high-quality circumlocutions they are likely to make. That being said, it was also interesting to note that the strongest students in both 
groups produced less extensive responses than the average response range for their respective groups. For instance, Candidate 6 in the intervention group used 348 words (group level mean $=450$ ), while Candidate 4 in the comparison group, who was also a grade level 5 student, used 281 words (group level mean $=386$ ). This finding is supported by other studies showing that high proficiency level students use fewer CSs (Chen 1990; Prebianca 2009).

Regarding the use of metacognitive strategies (RQ2), the findings in the present study suggest that conscious attention to a CS may lead to more frequent use of that strategy. As for the strategies taught in this study, the students in both groups more frequently used those CSs that they were consciously aware of. A conspicuous finding in this regard was the use of circumlocution, which all of the intervention group students and two of the comparison group students attended to. This was also the strategy most frequently employed. However, as some of the differences between the consciously applied CSs and those used without conscious attention were quite small, one must interpret the positive results from this analysis with caution. In addition, the contradictory statements regarding metacognitive strategies provided by some of the students make it difficult to draw firm conclusions on the effects of consciousness on the use of CSs. Overall, however, the modest positive association between these two variables, which were found in the present study, adds to the body of research literature which has shown a positive correlation between metacognition and learner strategies (Cohen 2011; Kongsom 2009; Nakatani 2005). Beyond this, we believe that there would have been an even stronger association between awareness and CS use if the metacognitive component had been more extensively and systematically treated in the intervention. The framing of the current teaching scheme prioritised the CS component, leaving only limited time for the modelling and practising of metacognitive CS use.

Regarding RQ3, we found no statistically significant relationship between grade level and CS use. However, the limited sample sizes $(n=22$ and $n=13$ ) may have been a restraining factor in this respect. Other studies have indicated that higher proficiency level students may be prone to using fewer strategies (Chen 1990; Prebianca 2009), as also evidenced in this study. Apart from this finding, the analyses yielded mixed and contradictory results.

Finally, in terms of RQ4, the questionnaire analyses provided little evidence of a positive correlation between motivation and CS use. Only one statistically significant, positive relationship was found between these variables. This association turned out to be moderate $(d=.399, p=.003)$. Consequently, it is difficult to draw firm conclusions concerning this association. However, there is qualitative evidence that CS teaching in itself may enhance students' positive feelings towards the use of strategies, which may in turn improve their performance (Kongsom 2009). A comment from Candidate 6 in this study, which was written on the questionnaire response sheet, 
supports Kongsom (2009): "Knowledge of these methods is a good thing because they make me more aware of how I can tackle difficult words at the exam".

Beyond these findings, there were some other comments made by the students in the interviews which provide interesting perspectives on CS use as well as the generalisability of the findings in this type of research. First, one needs to be aware of the contextual nature of communication in general, and of CS use in particular. For instance, in response to a question about what she would do if the communication task became really difficult, Candidate 2 answered: "It depends on the situation [. . .], for example, on whether it is just a regular task that you have to do in school ... or if it's . . let's say a [high-stakes] test . . . because that is much more serious". Second, and relatedly, there is the issue of anxiety, which may negatively affect communication. For instance, Candidate 10 mentioned "fear of saying something wrong" as a reason why she might be hesitant to speak English in real-life situations. Hence, one may infer that anxiety could have been involved in the production of strategies in this study.

\section{Conclusion and Implications}

The present study explored the impact of communication strategy instruction on communication strategy use among Norwegian EFL learners at the lower secondary school level. An important issue in this regard was the influence of metacognitive awareness on the students' employment of communication strategies. In addition, relationships between proficiency level and CS use, and between motivation and CS use, were studied. The results showed that the students who received training used a substantially higher number of strategies after instruction than the students who received no training. There were also indications that the students in the experiment group were metacognitively more aware of the communication strategies that they used more frequently. No correlation between proficiency level and strategy use was found, while the association between motivation and CS use was positive, but modest.

Three weaknesses in the study must be kept in mind. First of all, the student samples were small and purposefully selected. Hence, it is problematic to generalise beyond the research context. Second, no pre-test was distributed to the participants. This makes it difficult to firmly establish the impact of the strategy instruction on the students' use of these strategies. Third, the association between proficiency level and CS use on the one hand, and motivation and CS use on the other, was mainly based on the self-reported use of strategies. Although comparisons were made between the smaller test cohorts' use of strategies and those reported by the students in the larger questionnaire respondent samples, a strong relationship between these two measures could not be established. Still, the study provides some evidence of the usefulness of CS instruction and related factors that may contribute to 
the successful use of such strategies. Many of the findings are also supported by other studies examining the same phenomena.

As for the practical implementation of strategy use in EFL classrooms at this particular level, it seems that the use of achievement approaches such as the ones introduced here may be relevant in order to help students improve their language performance. There were also indications that the integration of explicit metacognitive strategy instruction into CS teaching schemes may be promising. However, we believe that even more time should be set aside for such teaching in order for the scheme to yield positive effects. In addition, we believe that the metacognitive component should be given more space, and that the whole instructional intervention should be carried out in an even more systematic manner than what was done in this study.

In terms of avenues for further research, we suggest that future studies recruit larger student samples when looking into the effects of metacognition on strategy use. In order to examine the students' metacognitive awareness, other research instruments, such as verbal protocol analysis, may provide relevant insights into students' conscious thinking when employing CSs (see Forbes 2018, this volume; Knospe 2018, this volume; Vold 2018, this volume, for examples of other methodological approaches to exploring learners' metacognition). Furthermore, other factors, such as contextual aspects, anxiety and self-efficacy beliefs, and their influence on CS use, should be examined. In addition, pre- and post-tests should include standardised tests (such as IELTS or TOEFL) in order to produce results that could be more easily compared across contexts.

\section{References}

Bialystok, Ellen. 1983. "Some Factors in the Selection and Implementation of Communication Strategies." In Strategies in Interlanguage Communication, edited by Claus Færch and Gabriele Kasper, 100-18. London: Longman.

- 1990. Communication Strategies: A Psychological Analysis of Second Language Use. Oxford: Blackwell.

Bøhn, Henrik. 2015. “Assessing Spoken EFL Without a Common Rating Scale.” SAGE Open 5 (4): 2158244015621956 . https://doi.org/10.1177/2158244015621956

- 2016. "What Is to be Assessed? Teachers' Understanding of Constructs in an Oral English Examination in Norway.” PhD diss., Department of Teacher Education and School Research, University of Oslo, Oslo.

Borger, Linda. 2014. "Looking Beyond Scores: A Study of Rater Orientations and Ratings of Speaking." Licentiate, Department of Education and Special Education, Gothenburg University.

Brown, Annie, Noriko Iwashita, and Tim McNamara. 2005. An Examination of Rater Orientations and Test-Taker Performance on English-for-AcademicPurposes Speaking Tasks. (TOEFL Monograph Series, TOEFL-MS-29). Princeton, NJ: Educational Testing Service. https://doi.org/10.1002/j.2333-8504.2005. tb01982.x

Chen, Si-Qing. 1990. “A Study of Communication Strategies in Interlanguage Production by Chinese EFL Learners." Language Learning 40 (2): 155-87. https//doi. org/10.1111/j.1467-1770.1990.tb01332.x 
Cohen, Andrew D. 2011. Strategies in Learning and Using a Second Language. 2nd ed. Harlow: Longman.

Corder, S. Pit. 1983. "Strategies of Communication.” In Strategies in Interlanguage Communication, edited by Claus Færch and Gabriele Kasper, 15-19. London: Longman.

Council of Europe. 2001. Common European Framework of Reference for Languages: Learning, Teaching, Assessment. Cambridge: Cambridge University Press

Creswell, John W. 2013. Qualitative Inquiry \& Research Design: Choosing Among Five Approaches. Los Angeles: Sage Publications Inc.

DeKeyser, Robert M. 2009. "Cognitive-Psychological Processes in Second Language Learning." In The Handbook of Language Teaching, edited by Michael H. Long and Catherine J. Doughty, 119-38. Malden: Wiley-Blackwell.

Dörnyei, Zoltán. 1995. "On the Teachability of Communication Strategies." TESOL Quarterly 29 (1): 55-85. https://doi.org/10.2307/3587805

- 2009. The Psychology of Second Language Acquisition. Oxford: Oxford University Press.

Dörnyei, Zoltán, and Mary Lee Scott. 1997. "Communication Strategies in a Second Language: Definitions and Taxonomies.” Language Learning 47 (1): 173-210. https://doi.org/10.1111/0023-8333.51997005

Ellis, Rod, and Gary P. Barkhuizen. 2005. Analyzing Learner Language. Oxford: Oxford University Press.

Færch, Claus, and Gabriele Kasper. 1983. "Plans and Strategies in Foreign Language Communication." In Strategies in Interlanguage Communication, edited by Claus Færch and Gabriele Kasper, 20-60. Harlow: Longman.

Forbes, Karen. 2018. “'In German I have to think about it more than I do in English'": The Foreign Language Classroom as a Key Context for Developing Transferable Metacognitive Writing Strategies." In Metacognition in Language Learning and Teaching, edited by Åsta Haukås, Camilla Bjørke, and Magne Dypedahl. New York: Routledge.

Haukås, Åsta. 2018. "Metacognition in Language Learning and Teaching: An Overview." In Metacognition in Language Learning and Teaching, edited by Åsta Haukås, Camilla Bjørke, and Magne Dypedahl. New York: Routledge.

Kellerman, Eric. 1991. "Compensatory Strategies in Second Language Research: A Critique, a Revision, and Some (Non-)implications for the Classroom." In Foreign/Second Language Pedagogy Research: A Commemorative Volume for Claus Ferch, edited by Robert Phillipson, Eric Kellerman, Larry Selinker, Michael Sharwood Smith, and Merrill Swain, 142-61. Clevedon: Multilingual Matters.

Kellerman, Eric, and Ellen Bialystok. 1997. "On Psychological Plausibility in the Study of Communication Strategies." In Communication Strategies: Psycholinguistic and Sociolinguistic Perspectives, edited by Gabriele Kasper and Eric Kellerman, 31-48. New York: Longman.

Knospe, Yvonne. 2018. "Metacognitive Knowledge about Writing in a Foreign Language-A Case Study.” In Metacognition in Language Learning and Teaching, edited by Åsta Haukås, Camilla Bjørke, and Magne Dypedahl. New York: Routledge.

Kongsom, Tiwaporn. 2009. "The Effects of Teaching Communication Strategies to Thai Learners of English." PhD diss., Faculty of Law, Arts and Social Sciences, University of Southampton, Southampton.

Lam, Wendy Y. K. 2010. "Implementing Communication Strategy Instruction in the ESL Oral Classroom: What Do Low-Proficiency Learners Tell Us?” TESL Canada Journal 27 (2): 11-30. https://doi.org/10.18806/tesl.v27i2.1056 


\section{Henrik Bøhn and Gro-Anita Myklevold}

Lærd Statistics. n.d. “Somer's D SPSS Statistics: Introduction.” https://statistics. laerd.com/premium/spss/sd/somers-d-in-spss.php.

Maleki, Ataollah. 2007. "Teachability of Communication Strategies: An Iranian Experience.” System 35 (4): 583-94. https://doi.org/10.1016/j.system.2007.04.001

Miles, Matthew B., A. Michael Huberman, and Johnny Saldaña. 2014. Qualitative Data Analysis: A Methods Sourcebook. Los Angeles: Sage Publications Inc.

Nakatani, Yasuo. 2005. "The Effects of Awareness-Raising Training on Oral Communication Strategy Use.” The Modern Language Journal 89 (1): 76-91. https:// doi.org/10.1111/j.0026-7902.2005.00266.x

Nakatani, Yasuo, and Christine C. M. Goh. 2007. "A Review of Oral Communication Strategies: Focus on Interactionist and Psycholinguistic Perspectives." In Language Learner Strategies, edited by Andrew D. Cohen and Ernesto Macaro, 207-27. Oxford: Oxford University Press.

Norwegian Ministry of Education and Research. 2006/2013. Lcereplan i engelsk [English Subject Curriculum]. Oslo: Author. Accessed September 21, 2017. http:// data.udir.no/k106/ENG1-03.pdf?lang=eng

NOU 2015: 8. 2015. Fremtidens skole-Fornyelse av fag og kompetanser [The School of the Future-Renewal of Subjects and Competences].

Poulisse, Nanda.1990. The Use of Compensatory Strategies by Dutch Learners of English. Dordrecht: Foris.

Prebianca, Gicele Vergine Vieira. 2009. "Communication Strategies and Proficiency Levels in L2 Speech Production: A Systematic Relationship." REVISTA DE ESTUDOS DA LINGUAGEM 17 (1): 44.

Rahmani Doqaruni, Vahid. 2015. "A Critical Look at Communication Strategies: Possibilities for Future Research." Innovation in Language Learning and Teaching 9 (2): 130-42. https://doi.org/10.1080/17501229.2013.859261

Rossiter, Marian J. 2003. “'It's like chicken but bigger': Effects of Communication Strategy in the ESL Classroom." Canadian Modern Language Review 60: 105-21. https://doi.org/10.3138/cmlr.60.2.105

Saldaña, Johnny. 2013. The Coding Manual for Qualitative Researchers. 2nd ed. London: Sage Publications.

Sasaki, Miyuki. 2014. "Introspective Methods." In The Companion to Language Assessment: Evaluation, Methodology, and Interdisciplinary Themes, edited by Antony John Kunnan, 1340-57. Chichester: Wiley-Blackwell.

Scullen, Mary Ellen, and Sarah Jourdain. 2000. "The Effect of Explicit Training on Successful Circumlocution: A Classroom Study.” In Form and Meaning: Multiple Perspectives, edited by James Lee and Albert Valdman, 231-53. Boston: Heinle.

Selinker, Larry. 1972. "Interlanguage." International Review of Applied Linguistics in Language Teaching 10 (1-4): 209. https://doi.org/10.1515/iral.1972.10.1-4.209

Tarone, Elaine. 1980. “Communication Strategies, Foreigner Talk, and Repair in Interlanguage.” Language Learning 30 (2): 417-28. https://doi.org/10.1111/j.14671770.1980.tb00326

Vold, Eva Thue. 2018. "Using Machine Translated Texts to Generate L3 Learners' Metalinguistic Talk." In Metacognition in Language Learning and Teaching, edited by Åsta Haukås, Camilla Bjørke, and Magne Dypedahl. New York: Routledge.

Williams, Jessica, Rebecca Inscoe, and Thomas Tasker. 1997. "Communication Strategies in an Interactional Context: The Mutual Achievement of Comprehension." In Communication Strategies: Psycholinguistic and Sociolinguistic Perspectives, edited by Gabriele Kasper and Eric Kellerman, 304-22. Harlow: Longman. 
Zhang, Donglan, and Christine C. M. Goh. 2006. "Strategy Knowledge and Perceived Strategy Use: Singaporean Students' Awareness of Listening and Speaking Strategies.” Language Awareness 15 (3): 199-219. https://doi.org/10.2167/ la342.0

Zhang, Lawrence J., and Tony Limin Qin. 2018. "Validating a Questionnaire on EFL Writers' Metacognitive Awareness of Writing Strategies in Multimedia Environments." In Metacognition in Language Learning and Teaching, edited by Åsta Haukås, Camilla Bjørke, and Magne Dypedahl. New York: Routledge. 


\section{Appendix}

Table 10A.1 Intervention group $(n=5)$. Extensive overview of CSs used.

Cand. 6 Cand. 7 Cand. 8 Cand. 9 Cand. 10 TOTAL (No. 6) (No. 10) (No. 12) (No. 13) (No. 14)

\begin{tabular}{lrrrrrr}
\hline Gender & Female & Male & Male & Male & Female & \\
Grade & 5 & 3 & 2 & 4 & 4 & \\
Number of words used & 348 & 596 & 276 & 724 & 307 & \\
GOOD QUALITY CS & & & & & & \\
Approximation & 5 & 4 & 2 & & 2 & 12 \\
Circumlocution-Good & 12 & 5 & 3 & 15 & 5 & 40 \\
Superordination & 6 & 4 & 2 & 8 & 2 & 22 \\
Stalling strategies (fillers) & 4 & 10 & 1 & 7 & 4 & 26 \\
SUM & 27 & 23 & 8 & 30 & 13 & 101 \\
MEDIUM QUALITY CS & & & & & & \\
All-purpose words & 1 & 11 & 1 & 6 & 4 & 23 \\
Circumlocution-Neutral & 4 & 7 & 3 & 12 & 10 & 36 \\
Message reduction & & 3 & 2 & & & 5 \\
Restructuring & 1 & 9 & 5 & 8 & 2 & 25 \\
Retrieval & 1 & 2 & & & 2 & 4 \\
Self-repetition & 2 & 1 & 8 & 2 & 14 \\
Self-rephrasing & 14 & 11 & 23 & 9 & 11 & 48 \\
Use of fillers & & 3 & 1 & 5 & 1 & 10 \\
Verbal strategy markers & 21 & 48 & 36 & 52 & 32 & 189 \\
SUM & & & & & & \\
$\begin{array}{l}\text { POOR QUALITY CS } \\
\text { Circumlocution-Poor }\end{array}$ & 4 & 10 & 5 & 6 & 4 & 29 \\
Code-switching & & 1 & 4 & & 3 & 8 \\
$\begin{array}{l}\text { Foreignising } \\
\text { Literal translation }\end{array}$ & & & 4 & 1 & & 5 \\
$\begin{array}{l}\text { Message abandonment } \\
\text { Mumbling }\end{array}$ & 2 & 8 & 2 & 7 & 2 & 21 \\
SUM & 6 & 23 & 19 & 18 & 9 & 75 \\
TOTAL USE OF CSs & 53 & 94 & 63 & 100 & 54 & 365 \\
\hline
\end{tabular}


Table 10A.2 Comparison group $(n=5)$.

\begin{tabular}{|c|c|c|c|c|c|c|}
\hline & Cand. 1 & Cand. 2 & Cand. 3 & Cand. 4 & Cand. 5 & TOTAL \\
\hline Gender & Male & Female & Female & Female & Male & \\
\hline Grade & 3 & 4 & 4 & 5 & 3 & \\
\hline Number of words used & 496 & 473 & 265 & 281 & 399 & \\
\hline \multicolumn{7}{|l|}{ GOOD QUALITY CSs } \\
\hline Approximation & & & & 2 & 5 & 7 \\
\hline Circumlocution-Good & 3 & 15 & 5 & 3 & 8 & 34 \\
\hline Superordination & 1 & 2 & 3 & 2 & 3 & 11 \\
\hline Stalling strategies (fillers) & & 2 & & & 1 & 3 \\
\hline SUM & 4 & 19 & 8 & 7 & 17 & 55 \\
\hline \multicolumn{7}{|l|}{ MEDIUM QUALITY CSs } \\
\hline All-purpose words & & 7 & 4 & 1 & 5 & 17 \\
\hline Circumlocution-Neutral & 7 & 12 & 5 & 5 & 11 & 40 \\
\hline Message reduction & & & & 2 & & 2 \\
\hline Restructuring & 2 & 4 & & & 4 & 10 \\
\hline Retrieval & & & 1 & & & 1 \\
\hline Self-repetition & 4 & & & 3 & 8 & 7 \\
\hline Self-rephrasing & 4 & 1 & & 2 & & 7 \\
\hline Use of fillers & 2 & 4 & & 6 & 6 & 18 \\
\hline Verbal strategy markers & 3 & & & 2 & & 3 \\
\hline SUM & 22 & 34 & 10 & 21 & 27 & 114 \\
\hline \multicolumn{7}{|l|}{ POOR QUALITY CSs } \\
\hline Circumlocution-Poor & 7 & 2 & 1 & 3 & 2 & 15 \\
\hline Code-switching & 6 & 1 & & & 2 & 9 \\
\hline Foreignising & 4 & & 1 & & & 5 \\
\hline \multicolumn{7}{|l|}{ Literal translation } \\
\hline Message abandonment & 8 & 6 & 3 & 2 & 4 & 23 \\
\hline Mumbling & 2 & & 1 & 1 & 1 & 5 \\
\hline SUM & $2 \overline{7}$ & 9 & 6 & 6 & 9 & 57 \\
\hline TOTAL USE OF CSs & 53 & 62 & 24 & 34 & 53 & 226 \\
\hline
\end{tabular}

